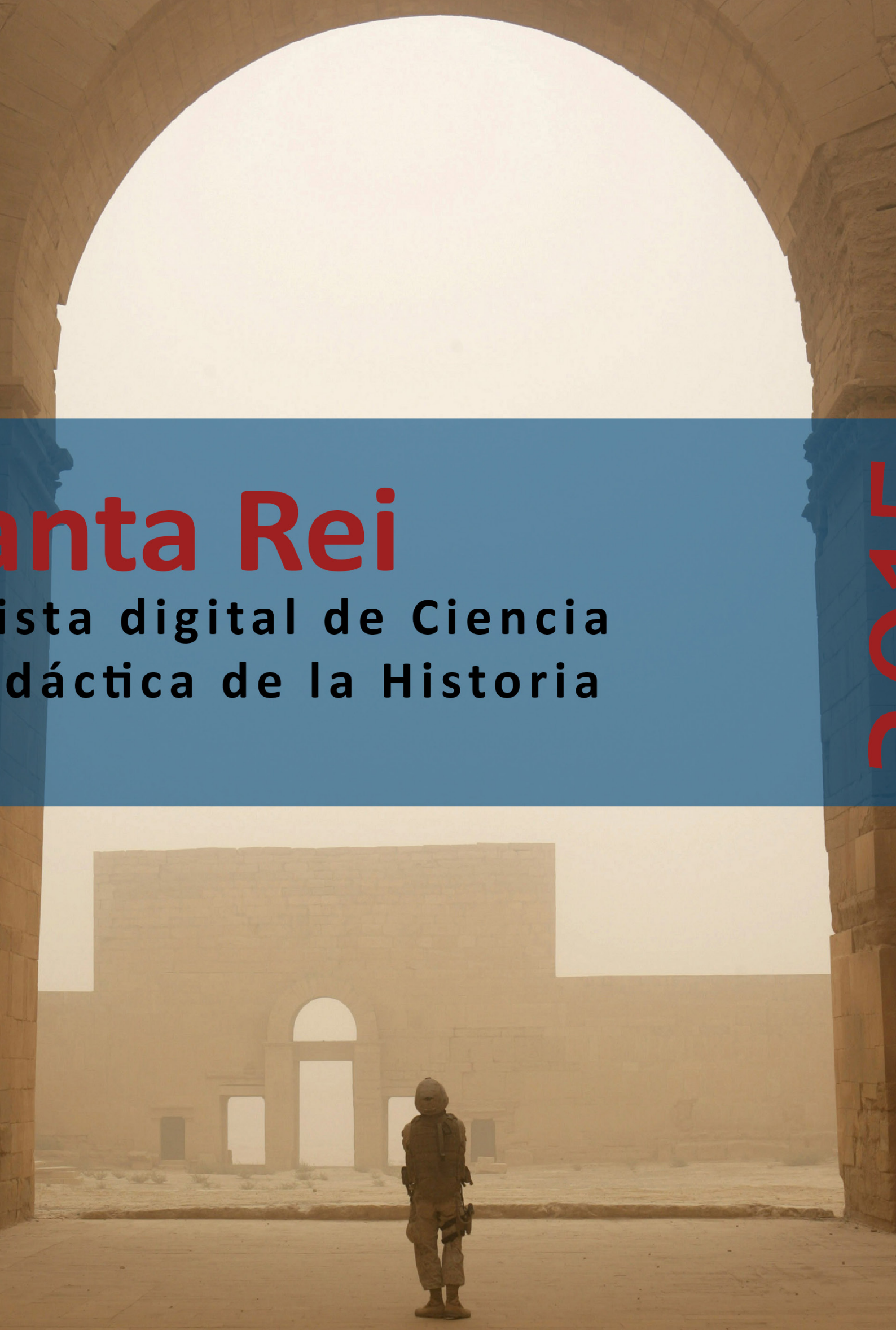

Revista digital de Ciencia y Didáctica de la Historia 


\section{Panta Rei \\ Revista Digital de Ciencia \\ y Didáctica de la Historia}

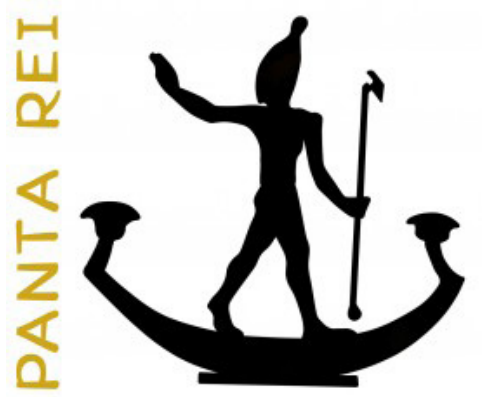

\section{5}

Revista anual

Fecha de inicio: 1995

Revista Panta Rei. pantarei@um.es

Edita:

Centro de Estudios del Próximo Oriente y la Antigüedad Tardía - CEPOAT

Edificio Universitario Saavedra Fajardo.

Universidad de Murcia

C/ Actor Isidoro Máiquez, 9

30007 - MURCIA - ESPAÑA

Teléfono: (+34) 868883890

cepoat@um.es

Web: www.um.es/cepoat/pantarei

Edición 2015

ISSNe: 2386-8864

ISSN: 1136-2464

Depósito legal: MU-966-1995
cepoAt

UNIVERSIDAD DE MURCIA centro de estudios del próximo oriente y la antigüedad tardía

En Portada: Ruinas de Hatra (Irak) (Fotografía de: Lance Cpl. Albert F. Hunt, U. S. Marine Corps).

Responsables de los textos: Sus autores.

Responsable de la presente edición: Consejo Editorial Panta Rei. 


\section{CONSEJO DE REDACCIÓN}

\section{Coordinador editorial}

Egea Vivancos, Alejandro

[Didáctica de las Ciencias Sociales, UMU]

\section{Editores}

Botí Hernández, Juan Jesús

[CEPOAT, UMU]

Meseguer Gil, Antonio José

[CEPOAT, UMU]

Sáez Giménez, David Omar

[CEPOAT, UMU]

Sánchez Mondéjar, Celso Miguel

[CEPOAT, UMU]

\section{Secretaria}

Arias Ferrer, Laura

[Didáctica de las Ciencias Sociales, UMU]

\section{Responsable informático}

Martínez García, José Javier

[CEPOAT, UMU]

\section{Traducción y corrección lingüística}

Martínez Martínez, Cristina

[Sociedad Española de Lenguas Modernas]

\section{CONSEJO ASESOR}

Albero Muñoz, M. ${ }^{a}$ del Mar [H. ${ }^{a}$ del Arte, UMU]

Chapman, Arthur

[History Education, UCL, Reino Unido]

Cobacho López, Ángel

[Derecho, UMU]

Egea Bruno, Pedro M. ${ }^{\text {a }}$

[Historia Contemporánea, UMU]

García Atienzar, Gabriel

[Prehistoria, UA]

González Monfort, Neus

[Didáctica de las Ciencias Sociales, UAB]

Haber Uriarte, María

[Prehistoria, UMU]

Irigoyen López, Antonio

[Historia Moderna, UMU]

Mahony, Simon

[Digital Humanities, UCL, Reino Unido]

Marsilla de Pascual, Francisco Reyes

[Técnicas historiográficas, UMU]

Miralles Maldonado, José Carlos

[Filología Clásica, UMU]

Molina Gómez, José Antonio

[Historia Antigua, UMU]

Noguera Celdrán, José Miguel

[Arqueología, UMU]

Pérez Molina, Miguel Emilio

[Filología Clásica, UMU]

Prados Martínez, Fernando

[Arqueología, UA]

Sánchez Ibáñez, Raquel

[Didáctica de las Ciencias Sociales, UMU]

Sancho Gómez, Miguel Pablo

[Educación, UCAM]

Vilar García, María José

[Historia Contemporánea, UMU] 

Artículos

El patrimonio arqueológico iraquí y su destrucción a lo largo del tiempo.

Fernando Espejel Arroyo.

Tacita Muta y el silencio femenino como arma del patriarcado romano.

Sara Casamayor Mancisidor.

Espartaco en la arqueología.

Juan Luis Posadas.

La batalla de Andagoste.

Luis Amela Valverde.

Las trabas para una formación arqueológica inclusiva.

Ana Samaniego Espinosa.

Repensando las narrativas nacionales: Un análisis del origen, transmisión e influencia en el aprendizaje histórico.

César López Rodríguez

El profesor como predicador, provocador y ermitaño. Un pre-texto para pensar las tareas de la didáctica de la historia.

Enrique Ibáñez Rojo

Entrevista

Evaluando el desarrollo de la competencia histórica en la enseñanza de la Historia en España. Entrevista a Jesús Domínguez Castillo.

María José Morales Rodríguez.

Reseñas

II Congreso de Jóvenes Investigadores del Mundo Antiguo de la Universidad de Murcia.

Pedro David Conesa Navarro y Juana M. ${ }^{a}$ Martínez Molina.

II Jornadas Internacionales de Didáctica de la Historia.

Eusebio Manuel Vidal Abellán.

Dölger, F. J. (2015). La luz de Cristo. Madrid: Ediciones Encuentro. 98 págs.

Alejandro Ruiz Sánchez.

Cooper, H. (ed.) (2013). Teaching History Creatively. Londres: Routledge. 185 págs.

Marta Gil de Sola Bellas.

El arte paleolítico en El Carnicero de Chabrol.

Alberto Lombo Montañés.

Normas de publicación/Publishing rules 



\title{
El patrimonio arqueológico iraquí y su destrucción a lo largo del tiempo
}

\author{
Iraqi archaeological heritage and its destruction throughout time
}

\author{
Fernando Espejel Arroyo ${ }^{1}$ \\ Universidad Autónoma de Madrid
}

Recibido: $12 / 03 / 15$

Aceptado: $18 / 08 / 15$

Para citar este artículo: Espejel Arroyo, F. (2015). El patrimonio arqueológico iraquí y su destrucción a lo largo del tiempo. Panta Rei. Revista Digital de Ciencia y Didáctica de la Historia, 9-25.

ISSNe: 2386-8864

DOI: http://dx.doi.org/10.6018/pantarei/2015/1

\section{Resumen}

El moderno país de Iraq ocupa una zona en la que se asentaron las principales culturas del Antiguo Oriente. Un rico patrimonio arqueológico que durante años el país se encargó de estudiar. Su glorioso pasado era el orgullo de la nación. Cuando en el año 2003 se producía la invasión de Iraq, los medios de comunicación publicaron noticias sobre el saqueo del Museo Nacional, sin embargo este no era sino un hecho más, probablemente el más doloroso de los que ha sufrido el patrimonio de este país a lo largo del tiempo. En primer lugar el expolio de las potencias colonizadoras europeas, interesadas en aumentar los fondos de sus museos, pasando por la presencia de mafias internacionales sin escrúpulos, varias guerras desastrosas y un embargo internacional que se prolongó durante doce años, agravando la ya de por sí delicada situación del país, y que tuvo consecuencias importantes para el patrimonio arqueológico.

\section{Palabras clave \\ Iraq, Patrimonio Arqueológico, Saqueo, Patrimonio Cultural, Próximo Oriente}

\begin{abstract}
The current country of Iraq is located in an area where the main cultures of the Ancient East settled down. A priceless cultural heritage which was studied by the country for years. Its majestic past was the pride of the nation. When Iraq was overrun back in 2003, the press published the looting of the National Museum, though it was not just an isolated event, but the most painful one the country had suffered throughout time. In the first place, the pillage from the European colonizing countries interested in increasing the collections of their own museums. Followed by the presence of international unscrupulous mafias, several disastrous wars and an international embargo which lasted for twelve years. All the mentioned episodes worsened even more the difficult situation of the country, which resulted in serious consequences for the cultural heritage.
\end{abstract}

\section{Key words}

Iraq, Archaeological Heritage, Looting, Cultural heritage, Middle East

1 Para contactar con el autor: Fernando Espejel Arroyo. Doctorando. Dpto. de Historia Antigua, Medieval y Paleografía y Diplomática. Universidad Autónoma de Madrid. Facultad de Filosofía y Letras (módulo II). Campus de Cantoblanco. Crta. Colmenar Viejo, km. 15 - 28049 Madrid. fernando.espejel@estudiante.uam.es 


\section{De viajeros, aventureros, estudiosos y cónsules}

Los trágicos acontecimientos sucedidos entre finales de febrero y comienzos de marzo de 2015, con la destrucción del museo de Mosul, varias estatuas aladas del yacimiento de Nínive y la destrucción de los yacimientos de Nimrud, Hatra y Dur Šarrukin por parte de milicianos yihadistas ha vuelto a poner de actualidad el maltrato al que se ve sometido desde hace mucho tiempo el patrimonio arqueológico de la región, castigado por choques de intereses que han provocado un sinfín de conflictos, destruyendo para siempre muchos de los restos y documentos que nos hubieran ayudado a comprender mejor la historia del Próximo Oriente, una historia que, al fin y al cabo, es la de todos.

Con el triunfo del Islam en las batallas de Yarmuk y al Qādisiyyah sobre bizantinos y sasánidas respectivamente, el conocimiento del mundo Oriental en Occidente se perdió, hubo que redescubrirlo. Quedaba la visión distorsionada y peyorativa que ofrecía la Biblia y las tradiciones antiguas, una visión que costó trabajo superar y en la que sobresalían personajes como Sardanápalo o Semíramis. A partir del siglo XII también contamos con una fantástica literatura de viajes que nos aporta datos que en ocasiones olvidamos en nuestro estudio. Benjamín de Tudela, Ibn Ŷubayr, Marco Polo, Leonhard Rauwolf, Pietro della Valle o García de Silva y Figueroa entre otros -personaje este último que encabezó la embajada de Felipe III al sha Abbás el Grande de Persia, y que fue el primero en proponer que las ruinas de Chilminara se trataban de la antigua Persépolis, mandando realizar las primeras representaciones realistas de los relieves e inscripciones de esta antigua capital persa, considerando que los signos tallados en la piedra se trataban de la escritura de los antiguos persas (Córdoba, 2005). Todos ellos, espíritus aventureros que a la vuelta de sus viajes publicaron sus experiencias, creándose toda una literatura de viajes sobre el Próximo Oriente (Invernizzi, 2005). Sin embargo no será hasta finales del XVIII y comienzos del XIX con la lucha entre Francia y Gran Bretaña, y más concretamente con la expedición de Napoleón a Egipto, cuando el interés por Oriente entre de lleno en Europa. A partir de este momento los grandes museos occidentales como el Louvre o el British Museum se lanzaron a por piezas con las que ampliar sus colecciones. En esta lucha entre Francia y Gran Bretaña ambas naciones deciden abrir consulados en el Próximo Oriente, lugar al que irán destinadas personas aficionadas a la arqueología. Cierto que a ellos les debemos los comienzos de las investigaciones en Oriente, pero también es verdad que todos tenían como objetivo la obtención de piezas con las que engrosar sus colecciones personales o las de los museos europeos (Gran-Aymerich, 1998). Uno de estos diplomáticos pioneros fue C. J. Rich, representante británico en Bagdad que vivió en Iraq entre 1808 y 1821 (Alexander, 1928). Rich era un apasionado de las antigüedades, realizó planos topográficos, hizo dibujos y esbozos muy interesantes de las ruinas, coleccionó monedas y piezas y efectuó un informe sobre las ruinas de Babilonia. Lo que aquí nos interesa es que recogió toda una serie de piezas que a su muerte, por expreso deseo de su viuda, pasaron a formar parte del British Museum. Pero las grandes colecciones de París y Londres se empezaron a formar gracias a los trabajos de P. E. Botta y A. $\mathrm{H}$. Layard, cónsules de Francia y Gran Bretaña respectivamente durante la década de los 40 del siglo XIX, y cuya labor será continuada por V. Place y H. Rassam². Tanto franceses como británicos llevaron a cabo investigaciones de mayor o menor calidad ${ }^{3}$, siendo unos auténticos pioneros en el

2 Durante el siglo XIX también encontramos en Oriente a personajes de la talla de J. F. Texier, P. Coste, W. L. Loftus, J. E. Taylor o J. Oppert por citar tan sólo a algunos de ellos, pero aquí nos centraremos en los que consideramos más importantes en lo que a formación de colecciones se refiere. Para una visión general sobre la historia de la investigación en Oriente llevada a cabo durante el siglo XIX y comienzos del XX consultar: Lloyd (1980), Larsen (1996), Córdoba (2001) o Fagan (2007).

3 La publicación de los trabajos franceses fueron de una extraordinaria calidad. Se trata de una obra de cinco volúmenes de una naturaleza sobresaliente. El problema de la obra de Botta (Botta y Flandin, 1849-1850), al igual que la posterior que publicaría $\mathrm{V}$. Place, residía en que se trataban de unos volúmenes monumentales imposibles de manejar, por lo que prácticamente su difusión fue nula. Por el contrario, los trabajos de A. H. 
trabajo de campo en Oriente.

\section{Las primeras reglamentaciones sobre la actividad arqueológica}

Esta situación hizo reaccionar a las autoridades turcas, hasta ese momento bastante permisivas a la hora de conceder permisos de excavación. El imperio Otomano se dio cuenta del valor que poseían las antigüedades y tomó conciencia de la necesidad de confeccionar una legislación que protegiesen su valiosísimo patrimonio. Con la experiencia de las leyes pioneras existentes en Grecia y Egipto que establecían que cualquier hallazgo pertenecía al país en que este se había producido, Turquía se dispuso a elaborar en marzo de 1869 la primera ley que prohibía las exportaciones de antigüedades de su territorio. Se trataba de una ley muy sencilla que prácticamente no tuvo aplicación, pero que dejaba bien clara las intenciones de las autoridades otomanas. La reglamentación de 1869 hacía incompatible la condición de funcionario y arqueólogo, pero pronto sería corregida por el Reglamento de 1874, una ley mucho más completa que la del 69 , organizada en treinta y seis artículos englobados en cuatro capítulos. Según la Reglamentación de 1874 toda antigüedad que aún no había sido descubierta pertenecía al gobierno otomano. El padre de esta nueva ley fue Osman Hamdi Bey (Pottier, 1910; Metzger, 1988; Chuvin, 2007), figura fundamental en la lucha contra el expolio y padre de la arqueología turca, prueba de ello es que hasta su entrada en acción todas las excavaciones en la región eran llevadas a cabo por europeos, animando Hamdi Bey el desarrollo de excavaciones nacionales. Hamdi Bey es un precedente en la protección del patrimonio en Oriente. El Reglamento de 1874 fue el primero verdaderamente eficaz. Gracias a él todos los objetos pasaban a ser propiedad del Estado y sólo se autorizaba a exportar moldes y dibujos. Fue una normativa que las autoridades europeas consideraron bastante dura, pero aun así, las Ordenaciones de 1884 dieron una mayor cohesión a este Reglamento de 1874. Fue bajo estas circunstancias cuando los alemanes desembarcan en Oriente, los auténticos renovadores de la ciencia, con una metodología totalmente novedosa. La arqueología en la región a comienzos del siglo XX estará dominada por misiones alemanas que trabajaran en Babilonia, Assur o Samarra, ya que los americanos y británicos abandonarán sus actividades. A los trabajos de R. Koldewey y W. Andrae le debe mucho la ciencia oriental, pero no debemos olvidar que a pesar del excelente trabajo que ambos realizaron en Babilonia o Asur, lo que impulsaba a la Deutsche Orient Gesellschaft (DOG) era la obtención de piezas que se instalarían en el recién creado Museo de Berlín (Del Cerro, 1999; Berndhardsson, 2005; Foster, Foster y Gerstenblith, 2005). Prueba de ello son la Puerta de Ištar o parte de la Vía de las Procesiones que hoy en día podemos admirar en el Pergamonmuseum de Berlín.

\section{El papel del patrimonio arqueológico en el Iraq independiente}

Así estaban las cosas cuanto tuvo lugar la I Guerra Mundial, que deparó la derrota del Imperio Otomano y la creación de un sistema de mandatos internacionales auspiciados por la Sociedad de Naciones, quedando el Próximo Oriente bajo la tutela de Francia y Gran Bretaña. Francia se hizo con el control de Siria y Gran Bretaña con el de Iraq, Arabia y Palestina. Este reparto resultó muy favorable a Gran Bretaña, pues dentro de su zona se encontraban los principales pozos de petróleo. Francia no contenta con esto elevó una protesta y consiguió que se revisase este reparto, pudiendo explotar a partir de entonces los pozos de petróleo de Kirkut.

Los territorios bajo control británico fueron administrados por Gran Bretaña como monarquías árabes, que pronto debían evolucionar hacia una independencia controlada. Iraq no fue una excepción. La persona escogida para llevar a cabo esta transición fue el rey Faysal, monarca

Layard (Layard, 1849; 1849-1853) en Nimrud o Nínive fueron de peor calidad, pero en cambio su obra alcanzó una gran popularidad.

Panta Rei (2015), 9 - 25 
hachemí, hijo de Hussein ibn Ali, que en junio de 1921 se quedó al frente del país aceptando el reparto realizado entre Francia y Gran Bretaña. Antes de coger las riendas del gobierno, Faysal se recorrió el país de arriba abajo, quedando fascinado por su patrimonio decidido a conservarlo y a hacer de él, junto a la educación, la bandera del nuevo país. Entre las personas que compartían este mismo sueño se encontraba Satti al-Husri, un antiguo funcionario de la administración otomana, nacionalista moderado y que había entrado en contacto con el mundo europeo. Satti sería el encargado de reformar la educación siguiendo sus ideas laicas y métodos de enseñanza racionales y modernos (Del Cerro, 2011). Consideraba que había que rescatar el pasado del país y trató de inculcárselo a la población, algo que en buena medida consiguió. Para Satti era indispensable asumir el pasado, para lo que era fundamental recuperar los monumentos en ruinas, acabar con el expolio y formar un gran museo nacional. Su caballo de batalla era acabar con la ignorancia a través de la educación. Gracias a las escuelas se creará un sentimiento nacional basado en un pasado glorioso, sin comparación a ningún otro, declarándose la nación árabe iraquí heredera de los antiguos sumerios, acadios, babilonios, árabes preislámicos e islámicos, omeyas, abasíes, tribus beduinas, campesinos y ciudades que habían sufrido la opresión otomana (Córdoba, 2004).

Pero en paralelo a Satti al Husri debemos hablar de Gertudre Bell, consejera y secretaria de asuntos orientales del alto comisionado para Iraq, Percy Cox. G. Bell también se encontraba interesada en las antigüedades, tanto que llegaría a obtener de manos de Faysal la responsabilidad sobre el patrimonio de la nación. En 1922 se creó el Departamento de Antigüedades con Bell como primera directora y se estableció una sala en el palacio del rey, la Saray, para recoger en ella los objetos que se encontrasen. Además, Gertrude Bell planteó una nueva regulación de las antigüedades. Basándose en las regulaciones otomanas de Hamdy Bey, G. Bell propuso una norma que permitiese el reparto de los hallazgos entre Iraq y las misiones europeas que dirigían excavaciones, con lo que en la práctica se seguía permitiendo el expolio de manera legal, volviendo las misiones occidentales a interesarse en reanudar los trabajos arqueológicos (Bernhardsson, 2005; Huot, 2008; Gibson, 2008b). A pesar de este duro revés la sala habilitada en el palacio comenzó a quedarse pequeña, en parte debido a los descubrimientos que la excavación patrocinada por el Museo Británico y el Museo de Arqueología y Antropología de la Universidad de Pennsylvania realizó en el Cementerio Real de Ur y a los de los alemanes en Warka, la antigua Uruk, por lo que unos años más tarde hubo de disponer de un pequeño edificio en la calle Ma`amun para que albergase las antigüedades que ya no cogían en la pequeña Saray, a cuyo frente había sido puesto Abdul Qadir al-Pachachi, un iraquí que había trabajado con anterioridad en los Archivos Turcos de Estambul (Al-Gailani, 2008). Pero en el plan de Satti también cobraban importancia las bibliotecas. La primera biblioteca pública de Bagdad fue fundada en 1919 debido al empeño de unos cuantos particulares, haciéndose cargo de ella a partir de 1929 el Ministerio de Educación que le dio el nombre de Biblioteca Pública. A la par, se fueron creando nuevas bibliotecas públicas tanto en la capital como en otras ciudades del país (Saleh, 2003a).

En 1932 Iraq obtiene la plena independencia y se crea el Departamento de Antigüedades y Patrimonio, derogándose todas las regulaciones que hacían posible el reparto de antigüedades, aprobándose leyes que pretendían preservar el patrimonio arqueológico de Iraq y terminar con la salida de piezas hacia Europa (Córdoba, 2004; Fales, 2006), especialmente tras la aprobación de una nueva y muy estricta ley de antigüedades en 1936 que establecía que todas las antigüedades y sitios arqueológicos eran propiedad del estado iraquí. (Gibson 2008b). Con esta nueva legislación, franceses y británicos dejaron de interesarse por las excavaciones en Iraq y, salvo pequeñas excepciones como la de S. Lloyd que excavaba para el Servicio de Antigüedades de Iraq, se marcharon a Siria. Sólo los alemanes con su misión en Warka, y los americanos en el valle del Diyala continuaron trabajando en Iraq, con lo que se produjo un vacío de expertos que para nada desanimó a Satti al Husri, sino todo lo contrario. Empujado por el prometedor futuro del patrimonio del país con su reciente independencia, decidió enviar al Instituto Oriental de Chicago a dos jóvenes estudiantes, el arqueólogo Fuad Safar y el epigrafista Taha Baqir, al tiempo que empezaba a concebir lo que en el futuro sería el Muthaf al-Watani (Museo Nacional) (Córdoba, 2003a) -más conocido por los 
turistas como Iraq Museum-. Llamó la atención de Satti al Husri un enorme solar situado en la parte occidental de Bagdad que también era codiciado por otros ministerios, así que ante la falta de dinero para crear un museo y adelantándose al resto de gabinetes que pudieran estar interesados, decidió levantar en este solar una réplica de unas de las puertas de Jorsabad siguiendo los dibujos de V. Place (Del Cerro, 2011) .

En 1936 con F. Safar y T. Baqir ya de vuelta y M. A. Mustafa, tiene lugar el comienzo de la investigación arqueológica iraquí, realizándose, con una calidad extraordinaria, excavaciones en Samarra y Dar al 'Imara y restaurándose monumentos como el Palacio Abasí de Bagdad; la Mustansiriya o el Jan Maryan entre otros (Córdoba, 2003a). Sin olvidar que todos estos trabajos se realizaban con la intención de crear un museo en un futuro próximo.

Las décadas de los 40 y 50 fueron años de luchas políticas que llevaron al exilio a multitud de nacionalistas árabes, entre los que se encontraba Satti al Husri, siendo tiempos de lucha entre una clase política nacionalista ansiosa de independencia y unas potencias europeas que pretendían seguir manteniendo su influencia sobre el petróleo. A mediados de los años 40 , empieza a publicarse Sumer, la primera revista científica árabe dedicada al estudio de las culturas antiguas. Pero la II Guerra mundial tuvo paralizadas las intervenciones arqueológicas extranjeras hasta la década de los 50. A pesar de las dificultades de estos años, nada impidió que se llevaran a cabo nuevas excavaciones -Tell Uqair (1940-1942), Aqar Quf (1942-1945), Tell Hassuna (1944), Eridu (19461949) o Hatra (1951)- y que los discípulos de Satti al Husri siguieran luchando por la creación de un gran museo nacional que recogiese la riqueza cultural de la nación. Además, en la década de los 50 se comenzó a excavar en Nimrud bajo las órdenes de M. Mallowan, unos trabajos que serían continuados después por D. Oates, además, con la revolución de 1958 prácticamente se eliminaron las excavaciones ilegales, una situación de estabilidad en el campo de los trabajos arqueológicos que se mantendría hasta 1990 (Córdoba, 2003b; Gibson, 2008b). El museo comenzó a construirse en 1957, pero no sería inaugurado hasta el 9 de noviembre de 1966 (Al-Gailani, 2008). Inauguración a la que fueron invitados los directores de los museos arqueológicos nacionales de toda Europa. Desgraciadamente, el director del Museo Arqueológico Nacional en ese momento, Luis Vázquez de Parga, declinó la invitación. Aun así el director de Antigüedades de Iraq, Faisal al Wailly, envió al Museo Arqueológico Nacional una carta en la que lamentaba la ausencia de representación española, junto a una medalla conmemorativa de dicha inauguración en la que en el anverso aparece representada la fachada del Museo Nacional de Iraq, unas manos que sujetan un vaso del que mana agua y que es el símbolo de la Dirección General de Antigüedades y el año de la inauguración, mientras que en el reverso una puerta, una lámpara y la leyenda: "El conocimiento y la justicia nacieron en Iraq" (Del Cerro, 2011). El tiempo que va desde la inauguración del museo hasta 1980, año en que comienzan las hostilidades contra Irán, pueden ser considerados los años de oro de la arqueología iraquí y el Museo Nacional (Córdoba, 2004).

El 17 de julio de 1968 el Partido Árabe Socialista Ba'az llega al poder, poniendo en marcha un programa de nacionalización del petróleo, lo que hizo de Iraq un país rico, impulsando la educación -mediante la creación de programas que intentaban solucionar el analfabetismo, algo que consiguieron a finales de la década de los 70- y aumentando el nivel de vida de la población. Se creó una infraestructura sólida incomparable a la de cualquier otro país del entorno (Saleh Alkhalifa, 2003b). De esta bonanza económica también se vio beneficiada la Dirección General de Antigüedades y los museos. La semilla que Satti al Husri había plantado en los años anteriores recogía sus frutos con una población absolutamente concienciada de su glorioso pasado y con la defensa de su patrimonio. Este era el verdadero valedor del patrimonio iraquí, el amor que los ciudadanos de Iraq sentían por sus antigüedades. Durante estos años se consiguió acabar con el saqueo. En el año 1970 se publicaba en Bagdad el Atlas de los lugares arqueológicos de Iraq, una

4 La misma puerta que con el bombardeo americano de 2003 sufrió el impacto de un misil que provocó un enorme boquete en el centro de la misma (George y Gibson, 2008). 
verdadera carta arqueológica que señalaba 12000 yacimientos catalogados de todas las épocas ${ }^{5}$, muchos de los cuales comenzaron a ser investigados por la Dirección General de Antigüedades. El gobierno se volcó con el patrimonio, poniendo a disposición de la Dirección General de Antigüedades unos medios económicos y humanos que ningún otro país podía imaginar. Los máximos exponentes de esta "edad de oro" de la arqueología iraquí que representaron los años 70 fueron Sabah A. Jassim y S. Salman al Rumaiydh. Con la ayuda de misiones extranjeras, fundamentalmente los tradicionales alemanes, ingleses, estadounidenses y franceses, a los que se unieron japoneses, belgas, italianos y austriacos, a principios de los 80 la Dirección General de Antigüedades de Iraq tenía abiertos doscientos yacimientos arqueológicos de manera simultánea, siendo la revista Sumer el principal medio donde eran publicados los resultados de la investigación. Es ahora cuando se descubren lugares como Tell es Sawwan, un lugar clave para el estudio de usos agrícolas, técnicas arquitectónicas, creencias y manufacturas artesanales en el IV milenio a.C., o en el valle del Hamrim varias misiones realizan importantes avances en nuestros conocimientos sobre la expansión de la cultura Obeid y la aparición de las primeras sociedades complejas (Jasim, 1985; Córdoba, 2003a). Pero no sólo se abrieron excavaciones arqueológicas. Otro de los ámbitos en los que se actuó fue en la restauración de lugares como Babilonia, Assur, Samarra, Nínive, Hatra, Dur Kurigalzu, o en edificios históricos de Arbil, Kirkut o Mosul. Además se abrieron museos y bibliotecas en cada capital de provincia, creándose un proyecto pionero hasta entonces como fue la creación del llamado "Museo de los Niños", adscrito al museo de Bagdad y pensado para niños menores de 10 años (Córdoba, 2003b). En 1975 el Museo Nacional de Bagdad cifraba su colección en más de 100000 piezas, la más importante de arqueología mesopotámica del mundo.

\section{La Guerra del Golfo y el embargo internacional}

Pero esta riqueza económica proporcionada por el petróleo, también iba a ser utilizada por el gobierno para llevar a cabo su proyecto de convertirse en una potencia dominante en la zona, lo que llevó a la invasión del vecino Irán a partir del 4 de septiembre de 1980. Se trató de una guerra muy costosa que movilizó a muchos científicos, gran parte de los recursos económicos que hasta entonces se dedicaban a la modernización del país fueron destinados a la compra de armas, convirtiéndose Iraq en el principal comprador dentro de este mercado. Paradójicamente, el $80 \%$ de las armas adquiridas entre 1980 y 1988, el tiempo que duró la guerra contra Irán, procedía de cuatro de los cinco miembros permanentes del Consejo de Seguridad de Naciones Unidas: EEUU, URSS, Francia y China, contando además el régimen de Sadam con una amplia ayuda del mundo occidental, especialmente de EEUU, país que no se cuestionaba lo más mínimo las políticas de Sadam Husseim (Saleh, 2003b). Esta guerra contra Irán terminaría ocho años más tarde, dejando dos países devastados y con cerca de un millón de muertos entre los dos bandos. Durante el tiempo que duró la confrontación el Museo Nacional permaneció cerrado y la actividad científica disminuyó considerablemente. Ante el beneplácito de las potencias occidentales en la invasión de Irán, Sadam se sintió fuerte y en agosto 1990 decidió invadir el vecino Kuwait. Esta vez Sadam se encontraría con la oposición internacional.

No es espacio éste para relatar los entresijos de aquel enfrentamiento, pero trataremos de esbozar unas mínimas pinceladas que permitan entender la situación de bloqueo impuesta por Naciones Unidas posteriormente. Las ansias expansionistas de Sadam Husseim con la intervención en Irán habían dejado a su país debilitado económicamente, por lo que las autoridades iraquíes decidieron invadir Kuwait, un país sobre el que reclamaban su soberanía por razones históricas, y

5 Paradójicamente, resulta desolador ver como de estos 12000 yacimientos que ya se catalogaban hace cuarenta años, solamente tres de ellos son considerados por la UNESCO Patrimonio de la Humanidad: Assur, Hatra y Samarra, lo que da muestra de la dejadez mostrada por esta institución durante todo este tiempo, especialmente durante los años que duró el bloqueo internacional tras la I Guerra del Golfo, de hecho, la UNESCO fue la única institución de la ONU que no pisó Iraq durante los años del embargo. 
además de esta manera intentar controlar el precio del petróleo y así poder permitirse la reconstrucción de Iraq (García y Sorroza, 2003). Ante esta situación, el 2 de agosto de 1990 las fuerzas armadas iraquíes comienzan la invasión de su vecino. Ese mismo día el Consejo de Seguridad de Naciones Unidas emitió la primera de las catorce resoluciones (Resolución 660) durante el tiempo que duró el conflicto (Maestro y Varea, 1997). En ella condenaba la invasión de Kuwait por parte de Iraq, apremiaba a los dos países a iniciar conversaciones y exigía Iraq su retirada inmediata ${ }^{6}$. Ante la negativa de Iraq a abandonar territorio kuwaití, el 6 de agosto se emitió una nueva Resolución (661), mediante la que se hacía efectivo el bloqueo internacional a Iraq. Posteriores resoluciones autorizaban el uso de la fuerza contra Iraq, provocando la por todos conocida como Guerra del Golfo. Esta guerra trajo consecuencias nefastas sobre el rico patrimonio iraquí. La propia UNESCO reconoció en su día que como consecuencia directa de las bombas de la coalición, respaldada por Naciones Unidas, resultaron dañadas las mezquitas Al Kawaz y Al Maaqal en la ciudad de Basora, la Mustansiriya de Bagdad o los yacimientos de Ur y Tell El Lahm, además de otros monumentos y edificios históricos. Una vez finalizada la guerra, la Dirección General de Antigüedades de Iraq remitió a la UNESCO una lista con los lugares que se habían visto afectados, parcial o totalmente, durante el conflicto y en las semanas inmediatas a la finalización del mismo. En esta misma carta se requería la ayuda internacional para la restauración del patrimonio afectado y la recuperación de los objetos robados, en total 13 museos regionales fueron saqueados y más de 5000 objetos sustraídos. Cabe señalar que todos los organismos internacionales a los que se solicitó ayuda se abstuvieron de enviar cualquier tipo de comisión que evaluase los daños. Gracias a esta carta sabemos que además de yacimientos arqueológicos o monumentos de interés, también resultaron afectados trece museos y seis bibliotecas fueron destruidas. Entre los museos dañados se encontraba el Museo Nacional de Bagdad, aunque la peor parte se la llevaron el Museo de Basora, el Museo de Maysan, el Museo de Kirkut, el Museo Etnográfico de Kirkut y el Museo de Kufa, que vieron como todos sus fondos fueron saqueados. En esta misma carta también se pedía ayuda internacional para restaurar los edificios afectados y recuperar los objetos sustraídos (Córdoba, 2000; Gibson 2008b). En los años posteriores al fin de la guerra, las excavaciones ilegales se dispararon, muchas de las piezas que conformaban los museos saqueados comenzaron a aparecer en el mercado ilegal de antigüedades. La magnitud de la catástrofe fue tal que las autoridades iraquíes pidieron la ayuda de la UNESCO y la INTERPOL para recuperar los objetos robados. Ante la falta de implicación de estas dos instituciones fue convocada en Bagdad en el mes de diciembre de 1994 una reunión a la que asistieron especialistas de diferentes países, que se encargaron de verificar y analizar la magnitud del saqueo. A esta reunión no asistió ningún miembro de la UNESCO o INTERPOL.

Los acuerdos alcanzados y la voluntad de los científicos asistentes de acabar con esta situación hizo reaccionar a la UNESCO, quien por medio de una carta de su Director General, el español Federico Mayor Zaragoza, realizaba una llamada a los distintos países para que se cumpliese lo firmado en la Convención sobre tráfico ilícito de bienes culturales de 1970 (Córdoba, 1997). Eso sí, Mayor Zaragoza, también señalaba que el mayor responsable en tomar medidas para evitar el saqueo de su patrimonio, es el propio país de origen de esas antigüedades. Vista semejante reacción del Director General de la UNESCO, no debe extrañarnos la actitud totalmente pasiva de esta institución ante los daños sufridos por el patrimonio iraquí durante y después de la guerra. Porque sí el resultado de la guerra fue catastrófico para el patrimonio, no lo iban a ser menos los posteriores doce años de embargo internacional al que una institución como la ONU -que en el capítulo 1 de su Carta dice tener como fines mantener la paz y la seguridad internacionales, fomentar las relaciones de amistad entre las naciones, o realizar la cooperación internacional en la solución de problemas internacionales de carácter económico, social, cultural o humanitario, entre otras cosas ${ }^{7}$ - sometió al pueblo iraquí, hundiéndole en la pobreza. También hay que recordar que

6 Todas las resoluciones del Consejo de Seguridad se pueden consultar en la página de Naciones Unidas: Recuperado de http://www.un.org/es/documents/sc/ (Consulta: 9-03-2015).

7 Artículo 1 de la Carta de las Naciones Unidas firmada el 26 de junio de 1945 y que entró en vigor el 24 de

Panta Rei (2015), 9 - 25 
tras la Guerra del Golfo, Iraq quedó dividido en tres bloques, siendo sólo soberano el gobierno iraquí en la parte central, con lo que el norte y el sur quedaron expuestos a la entrada de mafias que saquearon yacimientos, sobre todo en el sur. Así las cosas, a partir de 1994 se disparó el expolio de sitios arqueológicos, un ejemplo de ello es la cueva de Shanidar, excavada de manera ilegal por un equipo estadounidense que entró en Iraq por Turquía. Varios yacimientos del sur quedaron a merced de los saqueadores (Figura 1). Mafias internacionales sin ningún tipo de escrúpulos que en el año 1994 no tuvieron el más mínimo inconveniente en asesinar a Mr. Haddad, guarda de Larsa, para saquear este antiguo asentamiento (Córdoba, 2000). En el sitio de Nínive es donde mejor tenemos documentado el saqueo producido tras la guerra. En los años 70 y 80 Nínive había sido reconstruida y el yacimiento se hizo visitable. A comienzos de los $90 \mathrm{~J}$. M. Rusell visitó Nínive y realizó su tesis doctoral sobre los relieves de este lugar. En 1997 volvió a Nínive, fotografió los relieves y publicó una obra en la que podemos constatar que el deterioro de estos durante los años transcurridos entre sus dos visitas es evidente (Russell, 1998). Este comercio ilegal de antigüedades, se realizaba con países europeos o Estados Unidos entre otros, y ello a pesar que el embargo impedía la compra de cualquier objeto a Iraq. Las antigüedades eran sacadas del país a través del Kurdistán, Siria o Turquía, o directamente a través de Jordania, Arabia Saudí o Kuwait. Desde 1990 los Emiratos Árabes llegaron a ser el principal mercado de antigüedades iraquíes robadas, lo que dio lugar a la formación de grandes colecciones privadas. Sólo en contadas ocasiones la policía fronteriza llegaba a interceptar los objetos, ya que en la mayoría de los casos conseguían salir del país (Gibson, 2008a).
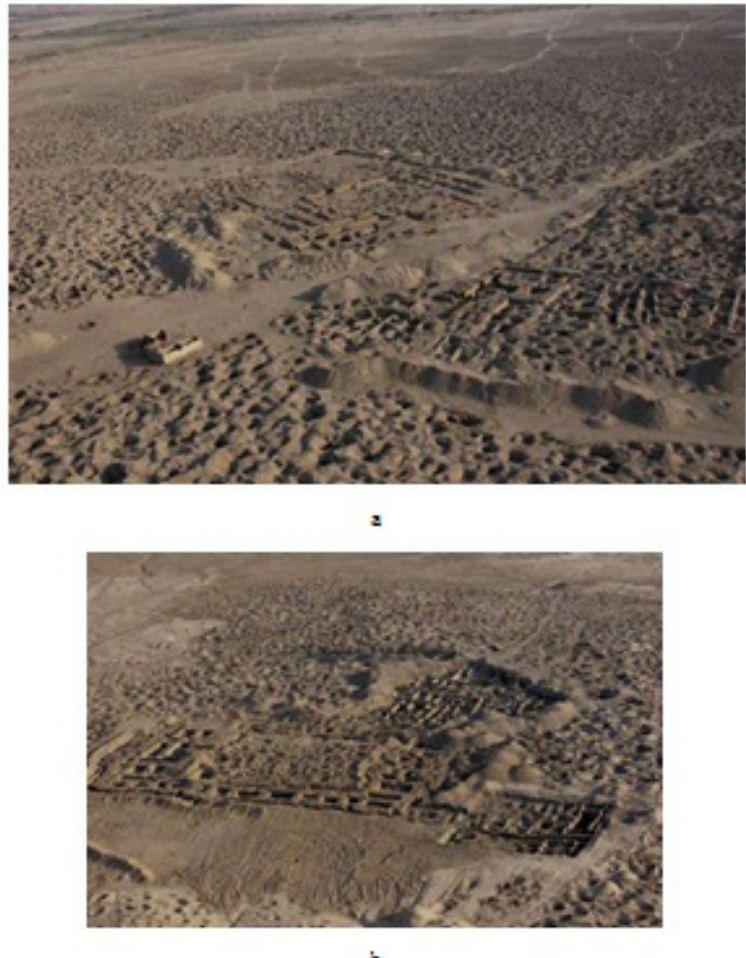

Figura 1: Yacimientos con cráteres provocados por excavaciones ilegales.

a) Umma, b) Zabalam (Russell, 2008: figs. 1 y 4)

El embargo estuvo vigente desde 1991 a 2003, año de la invasión anglo-estadounidense. Durante este tiempo se produjo el desmantelamiento de la estructura científica de Iraq y la situación solo fue a peor. A la salida cada vez mayor de especialistas del país y el saqueo de los yacimientos, hay que añadir la inexistencia de fondos para poder renovar bibliotecas, o la prohibición de importar

octubre del mismo año. 
productos químicos necesarios para la conservación de los objetos almacenados en los museos. Poco a poco se comenzó a trabajar por la recuperación de las piezas, y aparecieron publicaciones y bases de datos en donde se recopilaban los objetos desaparecidos (Reichel, 2008), de las que merecen especial atención los tres volúmenes de Lost Heritage. Antiquities Stolen from Iraq's Regional Museums (Gibson y McMahon, 1992; Baker, Matthews y Postgate, 1993; Fuji y Oguchi, 1996).

En 1996 también se ponía en marcha gracias al Centro di Scavi de Torino, el B.R.I.L.A. (Bureau for the Recovering and Investigating of the Iraqi Looted Antiquities), con una lista de objetos sustraídos que podían consultarse a través de su web8.

El Instituto Oriental de Chicago también creó una base de datos con una lista bastante completa de los objetos sustraídos ${ }^{9}$.

También en 1996 se celebraba en Madrid el International Court on Crimes against Humanity Comitted by the UN Security Council in Iraq, donde se reunieron diversos expertos entre los que se encontraba J. M. Córdoba, encargado de recoger los daños producidos en el patrimonio cultural y arqueológico ${ }^{10}$.

A pesar de todo la situación no mejoraba, los mercados de los países desarrollados como Inglaterra, Suiza, Japón, Estados Unidos o Israel estaban llenos de tablillas, fragmentos de relieves y todo tipo de antigüedades orientales (Gibson, 1997; Brodie 2008), algo que también se debía a la falta de interés de estos países por oponerse al mercado ilegal de antigüedades, un comercio sobre el que a menudo se suele ser más permisivo que con el comercio de drogas, pero que genera un nivel de ingresos ilícitos similar. El saqueo de yacimientos parecía imparable, algo que fue frenado, en parte, gracias a la introducción del programa "Petróleo por alimentos" puesto en marcha por parte de la ONU. La introducción de este programa ayudó a atenuar un poco las duras condiciones de vida de la población y se retomaron las excavaciones arqueológicas por parte de misiones europeas e iraquíes. En estos difíciles momentos para el patrimonio iraquí cobrará especial importancia la figura de D. George, descubridor de la ciudad de Umma, luchador incansable contra las mafias internacionales y gracias al cual a finales de los 90 pudieron reanudarse las excavaciones en yacimientos como Assur, bajo la dirección de P. Miglus, en Borsippa por el Institut für Sprachen und Kulturen des Alten Orients de la Universidad de Inssbruck, o en Uruk por el Instituto Arqueológico Alemán y el Instituto Francés de Arqueología del Próximo Oriente. En esta época se produjeron importantes descubrimientos en Umma, Umm al-Aqarib, Zabalam o Tell Schmid (Russell, 2008). Junto a Donny George hay que destacar la figura de Nawala al-Mutawali directora general de los museos de Iraq en el momento del saqueo. Los dos juntos formaron el alma de la lucha contra el saqueo del patrimonio arqueológico iraquí, aunque D. George tuvo que abandonar el país debido a los intentos de asesinato de los que fue víctima. Entre las excavaciones puestas en marcha a finales de los 90 me gustaría destacar de una manera especial el proyecto español Tell Mahuz, que si bien es cierto que se trata de un proyecto que comenzó en 1989-1990 no sería hasta 1997 cuando este se puso verdaderamente en funcionamiento de manera ininterrumpida hasta 2003. La excavación de Tell Mahuz fue llevada a cabo por una misión de la Universidad Autónoma de Madrid bajo la dirección de J. M. Córdoba, tratándose de la primera misión arqueológica española llevada a cabo en Mesopotamia.

Para terminar con este apartado del embargo internacional, no podemos dejar de indicar

8 Recuperado de http://www.centroscavitorino.it/progetti/iraq/brila.html (Consulta: 9-3-2015).

9 Recuperado de http://oi-archive.uchicago.edu/OI/IRAQ/dbfiles//raqdatabasehome.htm (Consulta: 9-32015).

10 En esta reunión, cuyo acta de acusación fue presentada por el ex-fiscal general de Estados Unidos, el señor Ramsey Clark participaron entre otros Peter Lewis Pellet exponiendo la situación nutricional en Iraq, Khaldun Darwix al-Bakri tratando la situación sanitaria en Iraq tras el embargo, Siegwart-Horst Günther analizando las consecuencias del uranio empobrecido sobre la población, Sarah Zaidi mostrando la situación de miseria en la que se vio envuelta la sociedad por culpa de las sanciones. Las conclusiones de esta reunión fueron recogidas en el libro editado por Maestro y Varela (1997). 
que todo el afecto que los iraquíes sentían por su pasado se perderá durante la década de los 90 (Gibson, 2008a; Rusell, 2008). Conscientes y orgullosos de su pasado, los iraquíes, ante las malas condiciones de vida comenzaran a vender todo tipo de objetos para así poder sobrevivir y superar una situación crítica, en buena parte provocada por el bloqueo impuesto por Naciones Unidas, perdiéndose de esta manera la principal protección de la que gozaba el patrimonio iraquí.

\section{La invasión de 2003 y sus efectos en el patrimonio}

Cuando en 2003 se produjo la invasión de Iraq con el posterior saqueo del Museo Nacional (George y Gibson, 2008) y diversos museos provinciales, sólo fue una etapa más en la sangría que llevaba sufriendo el patrimonio de Iraq desde hace muchos años, aunque eso sí, ha sido la que más eco alcanzó en los medios de comunicación. La intervención militar fue una cuestión bien planeada y debatida, por lo que hubo tiempo para poner varios objetos a salvo. Se excavaron trincheras delante del museo Las piezas más importantes fueron trasladadas a las cámaras acorazadas del Banco de Iraq, mientras que las que permanecieron en el Museo de Iraq al ser imposible su transporte se intentaron proteger con sacos de arena (Del Cerro, 2011). El problema es que a pesar de los esfuerzos por conseguir que las piezas no sufrieran daños, el museo se encuentra en un lugar central de Bagdad y en donde se produjeron los enfrentamientos.

El saqueo tuvo lugar entre los días 8 y 16 de abril, días que aprovecharon bandas organizadas para desvalijar el museo, robando piezas y destruyendo los archivos para que así fuese más complicado su posterior rastreo (Figura 2). El asalto al Museo Nacional lo tenemos bien documentado gracias a trabajos como los de Low (2003), Fales (2006), George (2008a; 2008b) Gibson (2008a) o George y Gibson (2008).

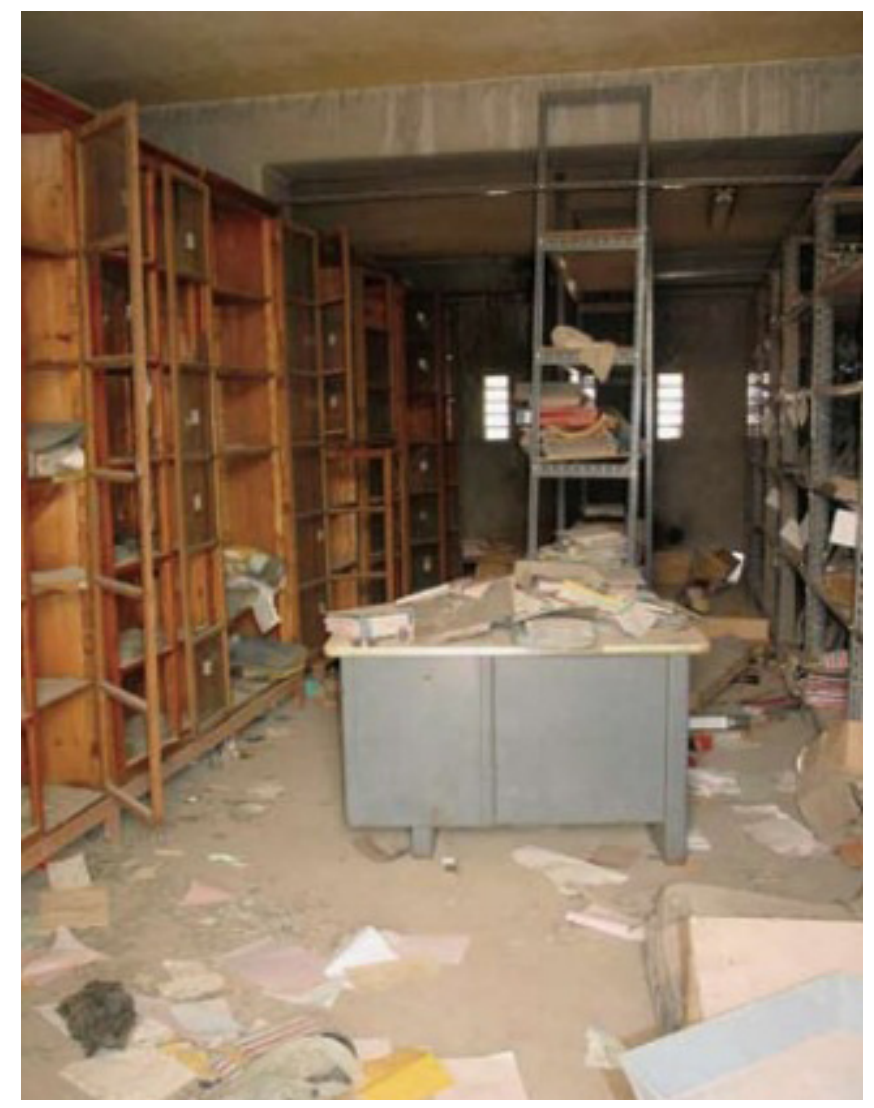

Figura 2. Sala del archivo del Museo Nacional de Bagdad tras el saqueo (George y Gibson, 2008: Fig. 3) 
Ante esta situación la UNESCO convocó una reunión el 17 de abril pero no contó con información oficial ni con ninguno de los conservadores del museo, acudiendo a ella especialista iraquíes en el exilio que no tenían conocimiento de lo que había sucedido. Pero esta reunión sí tuvo el valor de espolear las investigaciones americanas que comenzarían el 22 de abril (Del Cerro, 2011).

Se formó una comisión compuesta por catorce agentes militares y agentes civiles enviados por el Pentágono a cuya cabeza se encontraba el coronel Matthew Bogdanos con la misión de analizar lo sucedido. El informe concluía que en el Banco Central se encontraban las piezas más importantes como el tesoro de las tumbas reales de las reinas asirias de Nimrud. Tres de los cinco almacenes del museo fueron saqueados y varios miles de objetos robados o rotos ${ }^{11}$. El informe también recoge que en los primeros días de la ocupación, merced a la amnistía decretada para las personas que devolviesen piezas robadas, se recuperaron 915 objetos. Por lo que se refiere a los museos, todos los museos provinciales y sus respectivas bibliotecas fueron saqueados, mientras que en el de Bagdad se produjo la destrucción, de manera intencionada, del área administrativa, donde se rompieron 28 de las 451 vitrinas de la exposición, se robaron 42 grandes obras que por su tamaño no habían podido ser transportadas a otro lugar y se sustrajeron varios objetos de los almacenes del museo. Varias bibliotecas sufrieron robos o fueron devastadas por el fuego. La Biblioteca Nacional fue pasto de las llamas la noche del 11 al 12 de abril ante la indiferencia del ejército norteamericano, perdiéndose miles de libros antiguos y modernos. El Centro de Documentación y Manuscritos, que albergaba las primeras muestras de caligrafía árabe fue saqueado, y así, varias bibliotecas más.

Tras estas investigaciones tal y como muestra el trabajo de Low (2003) parece claro que el museo sufrió la acción de tres tipos de asaltantes. En primer lugar asaltantes que podríamos calificar como no profesionales que se llevaron todo lo que encontraron en su camino, provocando, además, graves daños y desperfectos en el museo. En segundo lugar, asaltantes pertenecientes a mafias organizadas perfectamente preparados y documentados para sustraer algunos de los objetos más importantes, encargándose de destruir las fichas y documentos para que no quedase rastro de ellos. Por último, el informe Bogdanos concluía que los objetos solo pudieron ser robados por los propios trabajadores que se quedaron dentro del museo, ya que eran los únicos que conocían donde se encontraban las llaves, obviando que las puertas de los almacenes habían sido forzadas y no abiertas con llaves. Aunque no queda recogido en el informe, por último debemos citar el testimonio de varios vecinos de los alrededores del museo y de varios trabajadores que aseguran que los marines también contribuyeron al saqueo, ya que fueron vistos saliendo con varias cajas del mismo (Del Cerro, 2011). Rápidamente varias de las piezas sustraídas del Museo Nacional y de otros lugares pasaron al mercado de arte de ciudades occidentales como Nueva York o Roma (Bailey, 2003).

No sólo los museos sufrieron daños, algunos yacimientos fueron víctima de los bombardeos. En los yacimientos del sur prosiguió el saqueo (el sitio de Isin ha sido calificado por la UNESCO como un yacimiento que ya no tiene nada que ofrecer, está completamente saqueado), y otros se vieron afectados por la actividad que en ellos desarrollaron las tropas invasoras, cuyos ejemplos más claros los encontramos en Babilonia (Moussa, 2008) o en Ur con la implantación de una base aérea en las proximidades del yacimiento durante el gobierno de $\mathrm{S}$. Husseim que se mantuvo en uso con las fuerzas de la Coalición e incluso se construyeron nuevas instalaciones (Hamdani, 2008).

\section{El patrimonio iraquí a partir de la caída de Sadam Husseim}

Tras la invasión militar el saqueo del patrimonio arqueológico continuó (Rothfield, 2008), a partir de 2003 comenzó a llevarse a cabo un programa por parte de varios arqueólogos que pretendía aleccionar a las tropas militares desplegadas en Iraq sobre la historia y la cultura del país

$11 \mathrm{EI}$ informe realizado por el coronel Bogdanos puede consultarse en: http://www.defense.gov/news/ Sep2003/d20030922fr.pdf

Panta Rei (2015), 9 - 25 
con la intención de concienciarles acerca de su valiosísimo patrimonio (Emberling, 2008). Varios centros de investigación arqueológica como el Centro di Scavi de Turín o varios Institutos franceses de arqueología promovieron la creación de bases de datos de los objetos sustraídos, la restauración de los que fueron dañados y el proyecto de reapertura del Museo Nacional de Bagdad (Parapetti, 2008; Lafont, 2008). En 2004 eran varios los miembros de museos, arqueólogos y conservadores iraquíes que viajaban al extranjero para seguir formándose, pero el saqueo de yacimientos prosiguió. Nada más fueron abandonados los trabajos en los yacimientos por la Dirección General de Antigüedades los saqueadores volvieron, el propio Consejero Cultural de la Coalición, el sr. Piero Cordone, pudo comprobar de primera mano a mediados de mayo de 2003 a bordo de un helicóptero de reconocimiento como decenas y centenas de saqueadores actuaban en Dhi Qar y Qadissiya ante la falta de medios de los guardas de la Dirección General de Antigüedades. Y es que durante el período de ocupación de la Coalición los principales esfuerzos en la lucha contra el saqueo de sitios arqueológicos corrieron a cargo de los carabinieri italianos (Zottin, 2008; Russell, 2008). Los años 2005 y 2006 no fueron mucho mejores para el patrimonio. Los problemas de seguridad y el asesinato de intelectuales que trajo como consecuencia la suspensión de los programas de posgrado agravó más si cabe la situación, además, la Dirección General de Antigüedades se encontraba en manos de seguidores del clérigo radical Muktadar al Sadar cuyo único interés estaba en proteger monumentos chítas (Del Cerro, 2011).

Ante la imposibilidad de visitar el Museo de Iraq, en 2009 la Dirección General de Antigüedades de Iraq y el Ministerio de Asuntos Exteriores italiano creó el proyecto The Virtual Museum Iraq ${ }^{12}$, donde puede realizarse una visita virtual por las piezas más importantes de algunas salas.

En el 7 ICAANE, celebrado en 2010 se informó de los intentos de algunos equipos iraquíes por reemprender los trabajos en yacimientos del sur y de la reanudación de los trabajos en Babilonia, a lo que hay que añadir que el Kurdistán aceptó la llegada de varias misiones arqueológicas extranjeras.

\section{La destrucción del patrimonio arqueológico en la actualidad}

A comienzos de esta última década parecía que el saqueo había sido parado. Además, a partir de la intervención militar de 2003, la UNESCO sí se involucró en la defensa del patrimonio y la situación política del país parecía ir normalizándose muy lentamente. Sin embargo, el desarrollo de la guerra en Siria con su expansión a Iraq ha provocado nuevos efectos sobre el ya maltrecho patrimonio iraquí. Con la intención de documentar los daños en el patrimonio sirio, protegerlo y documentarlo, en 2014 veía la luz por iniciativa del ASOR (American School of Oriental Research) y el Departamento de Estado de los Estados Unidos la ASOR Syrian Heritage Initiative ${ }^{13}$. En ella un equipo de expertos de diversas instituciones académicas realizan un notable esfuerzo no solo en documentar los desperfectos, sino en darlo a conocer pretendiendo concienciar a la población e intentando planificar una respuesta. Para ello, entre otras cosas, en su página web se encargan de recoger información, artículos y noticias de los medios de comunicación y revistas, publicando informes periódicos en los que actualizan la situación del patrimonio. Sin embargo la labor de la ASOR Syrian Heritage Initiative no se ha limitado a documentar la brutal destrucción a la que está siendo sometido el patrimonio sirio desde entonces, sino que también ha centrado su mirada en Iraq, sobre todo a partir de los graves acontecimientos en importantes museos y sitios arqueológicos iraquíes

A la paralización de todos los trabajos arqueológicos y los desperfectos causados por las contiendas hay que añadir una nueva catástrofe, la destrucción sistemática y deliberada del patrimonio histórico y religioso desde el primer momento en que DAESH, o Estado Islámico como es conocido popularmente en España, se hizo con el control de varias provincias iraquíes (Danti, Ali, Paulette, Franklin, Cuneo, Barnes Gordon y Elitzer, 2015). A pesar de que la ASOR Syrian Heritage

12 Recuperado de www.virtualmuseumiraq.cnr.it/ (Consulta: 9-3-2015).

13 Recuperado de http://www.asor-syrianheritage.org/ (Consulta: 28-5-2015). 
Initiative informaba de la posibilidad de que se estuviese llevando a cabo una destrucción deliberada del patrimonio en la provincia de Mosul (Danti, Ali y Moaz 2015), de varios santuarios en el centro y noreste de Iraq (Danti, Casana, Paulette, Franklin y Ali, 2015), de la Biblioteca Central de Mosul y en algunas estructuras históricas de la provincia de Nínive (Danti, Ali, Moaz, Paulette y Franklin, 2015), pero no será hasta finales de febrero de 2015 cuando en todos los medios de comunicación, nacionales e internacionales, se recogía la noticia de los destrozos causados el 26 de febrero por los milicianos del Estado Islámico en el museo de Mosul y en el yacimiento de Nínive, causando unos daños irreparables sobre el valiosísimo patrimonio que albergaban. En un video difundido por el propio Estado Islámico se puede ver como en el museo son destruidas esculturas de la ciudad de Hatra, así como varias esculturas originales y réplicas neoasirias de sitios arqueológicos del área de Mosul. En general, las piezas que se encontraban en el museo fueron sacadas para su venta en el mercado de antigüedades, mientras que las más grandes, difíciles de transportar, fueron directamente destruidas, entre estas últimas la mayoría de las esculturas asirias destrozadas eran réplicas, mientras que casi todas las procedentes de Hatra se trataban de originales. En el video también aparecen imágenes de varios individuos destruyendo los lamassu de la Puerta de Nergal en Nínive. Junto a los desperfectos mostrados en el video, por diversos medios también sabemos que en estas fechas se produjeron quemas de libros en bibliotecas de Mosul, se causaron daños en varios yacimientos, donde los mejores documentados son los producidos en la región de Tel Afar y se destruyó la mezquita al-Khidr (Danti, Zettler, Ali, Paulette, Moaz, Cuneo, Elitzer y Breegi, 2015). Como respuesta a estos salvajes actos el gobierno iraquí anunciaba la apertura del Museo Nacional de Iraq, cerrado desde la guerra del 2003, y que fue oficialmente reabierto por el primer ministro iraquí Haider al-Abadi el 28 de febrero de 2015.

Tras los ataques a Nínive y el museo de Mosul el estado islámico intensificó sus actuaciones contra el patrimonio y unos días más tarde les llegó el turno a las mezquitas de Hamou Qado y Sheikh Mohammad al-Abariqi, ambas en la ciudad de Mosul, a la vez que aumentaban las sospechas de que se estaban produciendo destrucciones en Nimrud, Hatra, Jorsabad y Assur (Danti, Zettler, Ali, Moaz, Paulette, Franklin, Cuneo y Elitzer, 2015). Pero, tal y como recogían los medios de comunicación de todo el mundo, serían los primeros días de marzo los peores para los grandes yacimientos iraquíes. El 5 de marzo arrasaban con los restos de la antigua Nimrud, situada a unos $30 \mathrm{~km}$ al sureste de Mosul en una nueva muestra de su fanatismo. No contentos con esto, dos días más tarde, el 7 de marzo, trasladaron su afán destructor a otros dos yacimientos situados en las cercanías de Mosul como son Hatra, la antigua capital de los partos, declarada por la UNESCO Patrimonio de la Humanidad, y a Jorsabad, en concreto a la antigua Dur Šarrukin, la capital asiria construida bajo el reinado de Sargón II. A parte de los videos publicados por Estado islámico poco es lo que sabemos sobre la situación en estos grandes yacimientos. El caso mejor conocido es el de Nimrud. El área que rodea este yacimiento se encontraba bajo control de ISIS desde junio de 2014 y a principios de enero salían a la luz unas fotos en las que parecía que el Palacio Noroeste había sido dañado, pero será el 5 de marzo cuando el ministro iraquí de turismo y antigüedades, además de numerosas fuentes afirmaban que el sitio había sido arrasado empleando vehículos pesados, y que el sitio fue saqueado antes de ser destruido. Un estudio más exhaustivo realizado con imágenes de satélites de alta definición el 7 de marzo mostraba una pequeña perturbación en la entrada al Salón del Trono del Palacio Noroeste. Una imagen del 1 de abril parece mostrar que desde entonces no se habían producido nuevos daños, aunque es cierto que en el caso de que se hubiesen causado destrucciones con equipos de mano como mazas o martillos mecánicos no se apreciarían a través de las imágenes por satélite. Sin embargo, el 11 de abril el Estado Islámico publicaba un video en el que varios de sus milicianos provocaban desperfectos en el yacimiento seguido por una gran detonación. Estos daños han podido ser confirmados con otra imagen, en este caso fechada el 17 de abril, que muestra ya el Palacio Noroeste completamente en ruinas (Figura 3). Según varios informes que no han podido ser confirmados por la ASOR Syrian Heritage Initiative el 2 de abril podría haber tenido lugar una detonación en el Palacio Noroeste (Danti, Branting, Paulette y Cuneo 2015). 


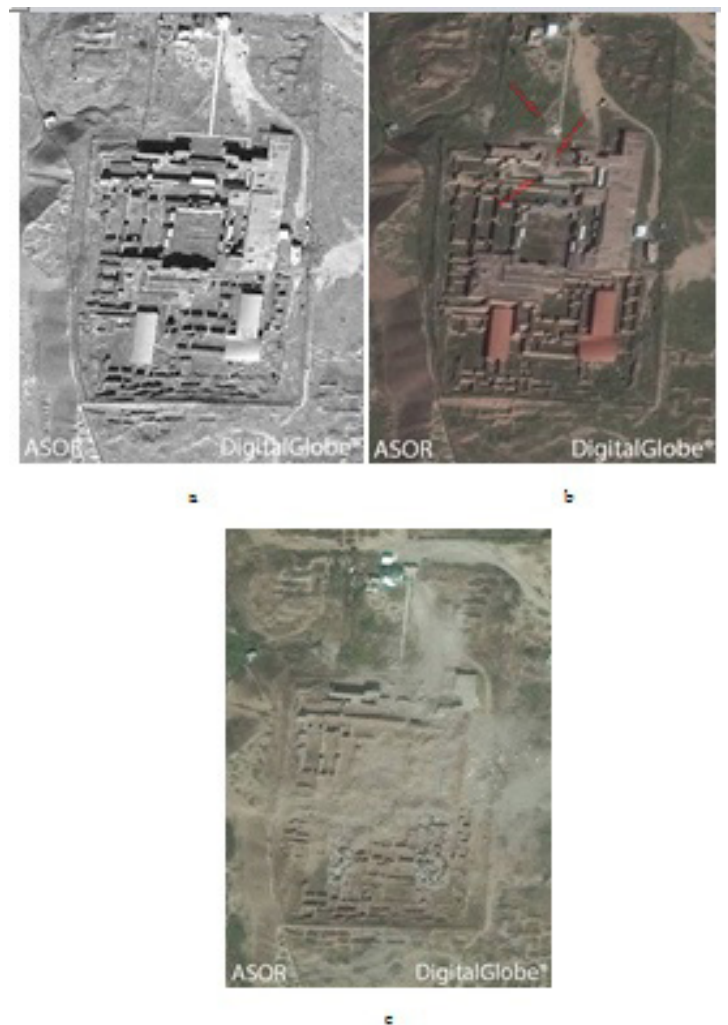

Figura 3. Palacio Noroeste de Nimrud. a) Imagen del 26 de febrero en la que no se aprecia ningún daño, b) Imagen del 7 de marzo con pequeños desperfectos en la entrada al Salón del Trono, c) Imagen del 17 de abril en la que el Palacio Noroeste aparece destruido (Danti, Branting, Paulette, y Cuneo, 2015)

Sin duda la provincia de Mosul ha sido la más castigada por el ISIS, y los días siguientes tras su entrada Hatra y las grandes capitales asirias, fueron destruidos edificios religiosos de esta provincia y otras cercanas como como los monasterios de St. George, Mar Behnam y Mart Sarah, las mezquitas de al-Sitt Nafisa, al-Sabunji y al-Imam Ibrahim, el minarete de Qutb al-Din Muhammad o el cementerio cristiano de Tel Kaif (Danti, Ali, Paulette, Franklin, Cuneo y Elitzer, 2015; Danti, Trevithick, Ali, Paulette, Cuneo, Franklin y Elitzer, 2015).

\section{Conclusión}

La destrucción que el patrimonio sufre en varias regiones del planeta, especialmente en Iraq y Siria, llevó a la Universidad de las Naciones Unidas y la UNESCO a celebrar una reunión el 6 de mayo en París con el título: Mobilization for Heritage: Iraq, Syria and other Conflict-Striken Countries. Afortunadamente, el nivel de daños en el norte de Iraq parece haber disminuido en el mes de mayo, sobre todo si los comparamos con los niveles que alcanzó en los meses precedentes. A su vez, los medios de comunicación han puesto su mirada en los saqueos y en el tráfico y venta de antigüedades sirias e iraquíes como medio de financiación del Estado Islámico y otros grupos extremistas (Danti, Ali, Paulette, Franklin, Cuneo, Barnes Gordon y Elitzer, D. 2015).

Así pues estos nuevos sucesos no hacen más que recordarnos el maltrato al que ha sido sometido a lo largo del tiempo el patrimonio arqueológico iraquí, testigo de una civilización verdaderamente fascinante que en tiempos pasados habitó esas mismas tierras y cuyos testimonios no podemos permitir que se pierdan. La destrucción de su patrimonio, junto con el sirio, es un drama que nuevamente está de actualidad y que hay que añadir a los muchos calvarios por los que ha tenido que pasar el pueblo iraquí en las últimas décadas. 


\section{Bibliografía}

Al-Gailani Werr, L. (2008). The Story of the Iraq Museum. En Stone, P. G. y Farchakh Bajjaly, J. (eds.), The Destruction of Cultural Heritage in Iraq (pp. 26-30). Woodbridge: Boydell.

Alexander, C. (1928). Baghdad in Bygone Days: from the journals and correspondence of Claudius Rich, traveller, artist, linguist, antiquary, and British resident at Bagdad, 1808-1821. Londres: J. Murray.

Bailey, M. (2003). Seized: over 600 objects looted from Iraq. The Art Newspaper, September, 1-3.

Baker, H. D., Matthews, R. J. y Postgate, J. N. (1993). Lost Heritage. Antiquities Stolen from Iraq's Regional Museums. Fascicle 2. Londres: British School of Archaeology in Iraq.

Bernhardsson, M. G. (2005). Reclaiming a plundered past. Archaeology and nation building in modern Iraq. Austin: University of Texas Press.

Botta, P. E. y Flandin, E. (1849-1850). Monument de Ninive. París: Gide et J. Baudry.

Brodie, N. (2008). The Market Background to the April 2003 plunder of the Iraq National Museum. En Stone, P. G. y Farchakh Bajjaly, J. (eds.), The Destruction of Cultural Heritage in Iraq (pp. 41-54). Woodbridge: Boydell.

Chuvin, P. (2007). Les Reinach et I'Empire ottoman. Comptes-rendus des séances de l'Académie des Inscriptions et Belles-Lettres, 151/2, 1091-1103.

Córdoba, J. M. (1997). Consecuencias de las sanciones sobre el patrimonio histórico-cultural de la Humanidad en Iraq. En Maestro, A. y Varea, C. (eds.), Guerra y sanciones a Irak: Naciones Unidas y el "nuevo orden mundial" (pp. 141-148). Madrid: Los Libros de la Catarata.

Córdoba, J. M. (2000). On the Iraq Museum and Other Assaults. Isimu, 3, 15-46.

Córdoba, J. M. (2001). Los pioneros de la arqueología en Oriente. Problemas y método en el redescubrimiento de asirios, babilonios y sumerios. En Córdoba, J. M., Jiménez, R. y Sevilla, C. (eds), El redescubrimiento de Oriente Próximo y Egipto. Viajes, hallazgos e investigaciones (pp. 59-80). Supplementa ad Isimu. II Series: Acta et Symposia, vol 1, Madrid: UAM publicaciones.

Córdoba, J. M. (2003a). La guerra y sus efectos sobre el patrimonio iraquí. Historia 16, 328, 1-27.

Córdoba, J. M. (2003b). Iraq, del esplendor arqueológico al expolio. La aventura de la historia, 57, 34-39.

Córdoba, J. M. (2004). Iraq: memoria y expolio. Robo y comercio ilegal de antigüedades 1991-2003. Nación Árabe, 51, 11-21.

Córdoba, J. M. (2005). Un caballero español en Isfahán. La embajada de don García de Silva y Figueroa al sha Abbás el Grande (1614-1624). Arbor, 180 (711-712), 645-669.

Danti, M. D., Ali, C. y Moaz, A. (2015). ASOR Cultural Heritage Initiatives (CHI): Planning for Safeguarding Heritage Sites in Syria and Iraq. Weekly Report, 24. Recuperado de Recuperado de www.asor-syrianheritage.org/weekly-reports/

Danti, M. D., Ali, C., Moaz, A., Paulette, T. y Franklin, K. (2015). ASOR Cultural Heritage Initiatives (CHI): Planning for Safeguarding Heritage Sites in Syria and Iraq. Weekly Report, 26-27. Recuperado de Recuperado de www.asor-syrianheritage.org/weekly-reports/

Danti, M. D., Ali, C., Paulette, T., Franklin, K., Cuneo, A., Barnes Gordon, L. A., y Elitzer, D. (2015). ASOR Cultural Heritage Initiatives (CHI): Planning for Safeguarding Heritage Sites in Syria and Iraq. Weekly Report, 39. Recuperado de Recuperado de www.asor-syrianheritage.org/ weekly-reports/

Danti, M. D., Ali, C., Paulette, T., Franklin, K., Cuneo, A., y Elitzer, D. (2015). ASOR Cultural Heritage Initiatives (CHI): Planning for Safeguarding Heritage Sites in Syria and Iraq. Weekly Report, 32. Recuperado de www.asor-syrianheritage.org/weekly-reports/

Danti, M. D., Branting, S., Paulette, T. y Cuneo, A. (2015). Report on the Destruction of the Northwest Palace at Nimrud. Nimrud Report. Recuperado de www.asor-syrianheritage.org/report-on-thedestruction-of-the-northwest-palace-at-nimrud/

Danti, M. D., Casana, J., Paulette, T., Franklin, K. y Ali, C. (2015). ASOR Cultural Heritage Initiatives $(\mathrm{CHI})$ : Planning for Safeguarding Heritage Sites in Syria and Iraq. Weekly Report, 25. 
Recuperado de Recuperado de www.asor-syrianheritage.org/weekly-reports/

Danti, M. D., Trevithick, M., Ali, C., Paulette, T., Cuneo, A., Franklin, K. y Elitzer, D. (2015). ASOR Cultural Heritage Initiatives $(\mathrm{CHI})$ : Planning for Safeguarding Heritage Sites in Syria and Iraq. Weekly Report, 33. Recuperado de Recuperado de www.asor-syrianheritage.org/weeklyreports/

Danti, M. D., Zettler, R., Ali, C., Moaz, A., Paulette, T., Franklin, K., Cuneo, A. y Elitzer, D. (2015). ASOR Cultural Heritage Initiatives $(\mathrm{CHI})$ : Planning for Safeguarding Heritage Sites in Syria and Iraq. Weekly Report, 31. Recuperado de Recuperado de www.asor-syrianheritage.org/ weekly-reports/

Danti, M. D., Zettler, R., Ali, C., Paulette, T., Moaz, A., Cuneo, A., Elitzer, D. y Breegi, D. (2015). ASOR Cultural Heritage Initiatives $(\mathrm{CHI})$ : Planning for Safeguarding Heritage Sites in Syria and Iraq. Weekly Report, 30. Recuperado de www.asor-syrianheritage.org/weekly-reports/

Del Cerro Linares, C. (1999). La figura y obra de Robert Koldewey. Cuadernos del seminario Walter Andrae, 1, 3-14.

Del Cerro Linares, C. (2011). El patrimonio arqueológico iraquí y su destrucción desde la Guerra del Golfo hasta nuestros días. Isimu, 14-15, 81-101.

Emberling, G. (2008). Archaeologists and the Military in Iraq, 2003-2008: Compromise or Contribution? Archaeologies: Journal of the World Archaeological Congress, 4/3, 445-459.

Fagan, B. M. (2007). Return to Babylon. Travelers, Archaeologists, and Monuments in Mesopotamia. Boulder: The University Press of Colorado.

Fales, F. M. (2006). Saccheggio in Mesopotamia. Il museo di Bagdag dalla nascita dell'Iraq ad oggi. Udine: Forum Editrice Universitaria, Udinese.

Foster, B. R., Foster, K. P. y Gerstenblith, P. (2005). Iraq Beyond the Headlines. History, Archaeology and War. Singapur: World Scientific.

Fuji, H. y Oguchi, K. (1996). Lost Heritage. Antiquities Stolen from Iraq's Regional Museums. Fascicle 3. Tokyo: Institute for Cultural Studies of Ancient Iraq, Kokushikan University.

García Encina, C. y Sorroza Blanco, A. (2003). Naciones Unidas: las obligaciones de Iraq. En Bardají, R. L. (ed.), Irak: Reflexiones sobre una guerra (pp. 97-113). Madrid: Real Instituto Elcano de Estudios Internacionales y Estratégicos.

George, D. (2008a). The Looting of the Iraq National Museum. CAA News, 33/3, 8-13.

George, D. (2008b). The Looting of the Iraq National Museum. En Stone, P. G. y Farchakh Bajjaly, J. (eds.), The Destruction of Cultural Heritage in Iraq (pp. 97-108). Woodbridge: Boydell.

George, D. y Gibson, McG. (2008) The looting of the Iraq Museum complex. En Emberling, G. y Hanson, K. (eds.), Catastrophe! The looting and destruction of Iraq's past (19-27). Chicago: The Oriental Institute of the University of Chicago.

Gibson, McG. (1997). The loss of archaeological context and the illegal trade in Mesopotamian antiquities. Culture Without context, 1, 6-8.

Gibson, McG. (2008a). The looting of the Iraq Museum in context. En Emberling, G: y Hanson, K. (eds.), Catastrophe! The looting and destruction of Iraq's past (pp. 13-18). Chicago: The Oriental Institute of the University of Chicago.

Gibson, McG. (2008b). The Acquisition of Antiquities in Iraq, 19 ${ }^{\text {th }}$ century to 2003, Legal and Illegal. En Stone, P. G. y Farchakh Bajjaly, J. (eds.), The Destruction of Cultural Heritage in Iraq (pp. 31-40). Woodbridge: Boydell.

Gibson, McG. y McMahon, A. (1992). Lost Heritage. Antiquities Stolen from Iraq's Regional Museums. Fascicle 1. Chicago: American Association for Research in Baghdad.

Gran-Aymerich, E. (1998). Naissance de l'archéologie moderne, 1798-1945. París: CNRS Éditions. Hamdani, A. (2008). The Damage Sustained to the Ancient City of Ur. En Stone, P. G. y Farchakh Bajjaly, J. (eds.), The Destruction of Cultural Heritage in Iraq (pp. 151-155). Woodbridge: Boydell.

Huot, J. L. (2008). The Importance of Iraq's Cultural Heritage. En Stone, P. G. y Farchakh Bajjaly, J. (eds.), The Destruction of Cultural Heritage in Iraq (pp. 19-24). Woodbridge: Boydell. 
Invernizzi, A. (2005). Il genio vagante. Babilonia, Ctesifonte, Persepoli in raconti di viaggio e testimonianze dei secoli XII-XVIII. Alessandria: Edizioni dell'Orso.

Jasim, S. A. (1985). The Ubaid Period in Iraq. Recent excavations in the Hamrim region. Oxford: BAR International Series.

Lafont, B. (2008). The ongoing work of the French Archaeological Institutes in the Middle East for Iraq. En Emberling, G. y Hanson, K. (eds.), Catastrophe! The looting and destruction of Iraq's past (pp. 221-228). Chicago: The Oriental Institute of the University of Chicago.

Larsen, M. T. (1996). The Conquest of Assyria. Excavations in an Antique Land. Londres: Routledge.

Layard, A. H. (1849). Nineveh and its Remains. Londres: John Murray.

Layard, A. H. (1849-1953). The Monuments of Nineveh, 2 vols. Londres: John Murray.

Lloyd, S. (1980). Foundations in the Dust. The Story of Mesopotamian Exploration. Londres: Thames and Hudson.

Low, Ü. (2003). Die Plunderung der kulturellen Einrichtungen in Irak unter besonder Berücksichtigung des Nationalmuseums in Bagdag. MDOG, 153, 13-56.

Maestro, A. y Varea, C. (eds.) (1997). Guerra y sanciones a Irak: Naciones Unidas y el "nuevo orden mundial". Madrid: Los Libros de la Catarata.

Metzger, H. (1988). La correspondance passive d'Osman Hamdi Bey. Comptes-rendus des séances de l'Académie des Inscriptions et Belles-Lettres, 132/4, 672-684.

Moussa, M. (2008). The damages sustained to the ancient city of Babel as a consequence of the military presence of Colition forces in 2003. En Stone, P. G. y Farchakh Bajjaly, J. (eds.), The Destruction of Cultural Heritage in Iraq (pp. 143-150). Woodbridge: Boydell.

Parapetti, R. (2008). The contribution of the Centro Scavi di Torino to the reconstruction to the Iraqi Antiquities. En Emberling, G. y Hanson, K. (eds.), Catastrophe! The looting and destruction of Iraq's past (pp. 229-234). Chicago: The Oriental Institute of the University of Chicago.

Pottier, E. (1910). Éloge funèbre de S. E. Hamdy Bey, directeur des Musées impériaux de Constantinple et correspondant étranger de l'Académie. Comptes-rendus des séances de I'Académie des Inscription et Belles-Lettres, 52/2, 71-75.

Reichel, C. (2008). Cataloging the Losses. En Emberling, G. y Hanson, K. Catastrophe! The looting and destruction of Iraq's past (pp. 51-63). Chicago: The Oriental Institute of the University of Chicago.

Rothfield, L. (2008). Antiquities under Siege: Cultural Heritage Protection after the Iraq War. Lanham: Altamira.

Russell, J. M. (1998). The Final sack of Nineveh. New-Haven-Londres: Yale University Press.

Russell, J. M. (2008), Efforts to Protect Archaeological Sites and Monuments in Iraq, 2003-2004. En Emberling, G. y Hanson, K. (eds.), Catastrophe! The looting and destruction of Iraq's past (pp. 29-43). Chicago: The Oriental Institute of the University of Chicago.

Saleh Alkhalifa, W. (2003a). Irak y el arte de escribir. La memoria destruida. Historia 16, 328, 28-41.

Saleh Alkhalifa, W. (2003b) ¿Choque de civilizaciones o choque de intereses? En Hijazi, A. (ed.), Irak: un mar de mentiras (pp. 163-180). Madrid: Olivium.

Zottin, U. (2008). Italian Carabineers and the protection of Iraqi cultural heritage. En Emberling, G. y Hanson, K. (eds.), Catastrophe! The looting and destruction of Iraq's past (pp. 235-240). Chicago: The Oriental Institute of the University of Chicago. 



\section{Panta Rei}

PANTA REI es una revista digital de investigación orientada a la Historia y otras ciencias afines. Su principal objetivo es la transmisión del conocimiento científico, dando una oportunidad también a los jóvenes investigadores que quieren abrirse camino en el estudio de las ciencias humanas y sociales. Se compone de estudios originales relacionados con la disciplina histórica así como su didáctica y difusión. Las diferentes secciones que componen la revista son: artículos de investigación, entrevistas a profesionales, recensiones de monografías de actualidad y crónicas de congresos o eventos científicos relevantes.

Todos los artículos publicados son objeto de un proceso de revisión a cargo de un mínimo de dos evaluadores, que se consideran expertos en el ámbito temático del artículo propuesto. Nuestro deseo es poder ofrecer unos contenidos rigurosos, de calidad y de interés.

EI CEPOAT (Centro de Estudios del Próximo Oriente y la Antigüedad Tardía de la Universidad de Murcia) es la institución encargada de la coordinación y gestión de la revista, desde donde anualmente se lanzará la convocatoria para aquellos que estén interesados en publicar sus trabajos, siempre relacionados con la Historia, Arqueología, Historia del Arte, Didáctica de las Ciencias Sociales, etc.

PANTA REI is a digital journal focused on History and other sciences related to it. Its main objective is the transmission of scientific knowledge by giving also an opportunity to young researchers who want to make their way in the study of human and social sciences. It is composed by original studies related to History, as well as its didactics and promotion. The different sections of this journal are: research articles, interviews to professionals, recensions on monographs about current issues and reports about congresses or relevant scientific events.

All the articles published are subject to a revision process carried out by a minimum of two reviewers who are considered to be experts in the field of the article proposed. Our wish is to offer rigorous contents with quality and being of interest to the reader.

CEPOAT (Centre of Studies of the Middle East and Late Antiquity of the University of Murcia) is the institution in charge of the coordination and management of this journal. This is the centre from where the call for papers will be launched for all the people interested in publishing their papers, always related to History, Archeology, Art History, Didactics of the Social Sciences, etc. 


\section{Normas de Publicación}

El autor se compromete a enviar trabajos originales, que no se encuentren publicados en otras revistas ni en otros idiomas. Así mismo, el mismo artículo no podrá ser presentado en otras revistas mientras dure el proceso de evaluación.

\section{Envío y presentación de originales}

Los artículos se enviarán exclusivamente a través del correo electrónico a la dirección pantarei@um.es. Los textos serán enviados en formato DOC y las imágenes en formato JPEG o TIFF, y con un tamaño mínimo de 2000 px. Éstas no aparecerán incorporadas en el texto, sino enviadas en archivo aparte y correctamente numeradas según su posición en el texto. Junto al trabajo, se rellenará y enviará un documento aparte en el que se especifiquen los datos del autor siguiendo el modelo disponible en la página Web de la revista.

Para la redacción de los trabajos se tendrá en cuenta el Manual de la American Psychological Association, en su sexta edición. La extensión máxima de los trabajos será de 30 páginas. La tipografía será Arial 11, con interlineado sencillo y sin espacio alguno entre párrafos. El texto deberá ir justificado a ambos márgenes y sin sangría en los primeros párrafos. Los márgenes serán de $2,50 \mathrm{~cm}$. En los casos en los que fuera necesario incorporar notas, éstas irán a pie de página, enumeradas consecutivamente, con tipografía Arial 10, interlineado sencillo y justificadas a ambos márgenes.

Una información más detallada se encuentra disponible en la página http://www.um.es/cepoat/ pantarei.

\section{Proceso de valoración y evaluación}

Una vez recibidos los trabajos, la Revista realizará una primera valoración. Si el trabajo enviado se ajusta a las normas de presentación propuestas, la temática es coincidente con la línea editorial de la revista y posee la calidad científica necesaria, será remitido al consejo asesor para una primera evaluación. Si no es así en este primer paso se puede rechazar directamente los documentos que incumplan claramente la línea editorial.

Será el Consejo Asesor quien indique a la revista la originalidad, relevancia, estructura, redacción, aparato bibliográfico, etc. del trabajo enviado y, para ello, se designará a dos revisores expertos externos que evaluarán cada uno de los trabajos, que pueden formar parte (o no) de este Consejo Asesor. La selección de los revisores se ajustará a la temática y características metodológicas del trabajo. El nombre y filiación de los autores serán eliminados del trabajo para su revisión, así como los revisores actuarán de manera anónima y confidencial.

Los revisores deberán rellenar un informe de evaluación que centrará su atención en aspectos tales como características formales, originalidad y novedad de los trabajos, relevancia de las propuestas y los resultados, calidad metodológica y validez científica.

Una vez terminado el proceso se decidirá la aceptación o no de los mismos y su publicación en el número que sea pertinente, así como las modificaciones susceptibles de ser realizadas para su final publicación. Dicha notificación se enviará únicamente por correo electrónico, en un plazo máximo de seis meses. 


\section{Publishing rules}

The author is committed to submit original papers not having been published in other reviews or in other languages. In this way, it is not allowed for the same paper to be presented in other reviews during the evaluation process.

\section{Submission and presentation of originals}

The articles will be exclusively submitted by email to pantarei@um.es. The texts will be submitted in DOC format and the images in JPEG or TIFF format, and with a minimum size of 2000 px. Images will not be integrated in the text but sent in another file and properly numbered according to their position in the text. Attached to the paper, a document will be filled out and sent where the author's data will be specified following the model available on the website.

The sixth edition of the Manual of the American Psychological Association will be taken into account for the writing of the papers. The length of the papers must not exceed 30 pages. Typography will be Arial 11 , with simple line spacing and no space between paragraphs. The text must be justified on both margins without indentation in the first paragraphs. Margins size will be $2.50 \mathrm{~cm}$. Where it could be necessary the incorporation of notes, they will be at the bottom of the page, consecutively numbered with typography Arial 10, simple line spacing and justified on both margins.

More detailed information is available on the website: http://www.um.es/cepoat/pantarei.

\section{Examination and assessment process}

The Journal will submit the papers to a first examination once received. If the paper follows the presentation guidelines, the subject agrees with the editorial line of this journal, and possess the scientific quality required, it will be sent to the advisory council for a first assessment. If not, the documents which clearly fail to complete the editorial line may be rejected straightaway in this first step.

The Advisory Council will indicate the originality, relevance, structure, writing, bibliography, etc. of the text to the journal; for this purpose, two outside experts will be designated to review the papers; these experts can be (or not) part of this Advisory Council. The selection of the experts will adjust to the subject and methodological characteristics of the paper. Name and affiliation of the author will be eliminated from the text for its review, in this way experts will act anonymously and confidentially.

The experts will fill out an assessment report which will focus on aspects such as formal characteristics, originality and novelty of the papers, relevance and results of the proposal, methodological quality and scientific validity.

Once the process is finished, the acceptance or not of the papers and its publication in the corresponding edition will be decided, as well as the modifications that may be done for its final publication. This notification will be sent by email within 6 months maximum. 

